\title{
Neue Varietät des Gummigutti von Mysore.
}

Den Baum, von welchem dieses Gummigutti entnommen wird, fand Cleghorn an der Nordwestgränze von Mysore in dichten Gebirgswäldern in der Hohe von 23000 Fuss wachsend, von Sagopalmen und andern hohen Bäumen überragt. Derselbe scheint während der Regenzeit zu blühen, wo er auch eine reichliche Menge Saft ausschwitzt; dieser führt bei den Eingeborenen den Namen Gorgiemara. Ein Stuick des eingetrockneten Saftes war an der Oberfläche braungelb und von Wachsglanz, wie feines siamesisches Gutli und zeigte einen muschligen Bruch. Mit Wasser lässt es sich zu einer Emulsion verreiben, welche eine schöne intensiv gelbe Farbe besitzt. Es unterscheidet sich, als Farbematerial benutzt, von dem feinsten siamesischen Röhrengulti nur durch einen geringen Stich ins Brïunliche und man kann es zu den besten Gultisorten rechnen. Das Gulli von Mysore hat eine analoge Zusammensetzung, wie das von Ceylon und Siam, welche früher von $\mathrm{R}$. Christison und später von Buchner untersucht worden sind. Die Analyse eines schönen ceylonischen Guttis gah) nach Christis on

$$
\begin{array}{rr}
\text { llarz..... } & 74,8 \\
\text { Gummi... } & 16,5 \\
\text { Farbstoff. } & 3,5 \\
\text { Holzfaser. } & 2,2 \\
\text { Wasser... } & 4,0 \\
\hline & 101,0
\end{array}
$$

Eine Analyse des Gultis von Mysore

$$
\begin{aligned}
& \text { Harz . . . . . . . } 77,0 \quad 80,0 \\
& \text { Gummi ......... 14,0 14,0 } \\
& \text { Farbstoff......... 5,0 } 5,0 \\
& \text { Holzfaser und Sand ... } \frac{3,0}{99,0} \quad \frac{0,5}{99,5}
\end{aligned}
$$

Demnach enthält also diese letztere Sorte mehr Farbstoff und Harz, aber weniger Gummi als die ceylonische, sie lässt sich aber eben so gut wie die letztgenannte zu einer Emulsion verreiben, auch wird durch die grössere Menge des braunen Farbstoffs ihr Werth als Farbematerial nicht vermindert, da sich dieser erst heim Abdampfen der weingeistigen Lösung an der Luft hildet.

Auch nach den damit angestellten Versuchen scheint das Gutti von Mysore ebenfalls mit dem von Siam und Ceylon in der arzneilichen Wirkung ubereinzustimmen.

Die Botanik des Guttis betreffend, so ist bekanntlich von Graham nachgewiesen worden, dass Linné und 
Murray zwoi verschiedene Pflanzen unter dem Namon Stalagmites beschrieben haben, und hat jenen Baum $\mathrm{He}$ bradendron cambogioides genannt, wäbrend W ight glaubt, dass man ihn nicht von dem Gemus Garcinia trennen diurfe. Die Garcinia Cambogia nach Roxburgh, von welcher man sonst fälschlich das Gutti horleitete, liefert gar kein Gutli, sondern ein geltes IIarz. welches atherisches Oel enthält und keine Emulsion giebt. Die Garcinia elliptica Wallich, welche Gummigutti liefert, ist nach Chr i st is o n zu dem Genus Hebradendron zu stellen, da die Merkmale, nach welchen sie sich nach $W i g h t$ davon unterscheidet, nicht constant sind. Die Mutterpflanze des Gutli von Mysore ist jedenfalls Garcinia pictoria Roxb, welche jedoch ebenfalls zu demGenus Uebradendron zu rechnen ist, so dass also das Gummigutti nur von einzelnen Arten dieser Gattung hergeleitet werden darf. (Pharm. Journ. and Transact. VI. - Pharm. Centralbl. 1×17. No. 11)

$B$.

\section{Galläpfel von Terebinthus und chinesische Galläpfel.}

Guibourt giebt eine genauc Beschreibung der in seinen Händen befindlichen Sorten.

I. Eckige oder gehörnte Galläpfel von Terebinthus.

Diese haben die Gestalt eines langen, abgeplatteten, in der Mitte erweiterten Bläschens, das an beiden Enden in eine Spitze zuläuft und der Radix Bistortae ähnlich ist. Ihre Länge und Breite variirt schr; ihre Farbe ist entschieden roth, besonders auf der Oberfläche. Die Dicke beträgt 1 Millimeter, im Innern hohl, nur finden sich einige Ueberreste von Insecten. Die Substanz ist compact, durchscheinend, mit holzigen Fasern gemischt; der Geschmack ist zusammenziehend, schwach aromatisch, ähnlich dem Terpentin von Chios, und dieser Charakter ist so bestimmt, dass dieses schon für die Abstammung von Terebinthus hinreichend erscheint. Diese Sorte, durch den Stich in eine Endknospe erzeugt, ist stets einfach und in eine einzige Spitze endigend.

II. Schwarze und gehörnle Gallipfel vom Pistacienbaum.

Wiewohl Guibourt diese Sorte einer Pistacie zuschreibt, so ist man doch jetzt zu der Vermuthung gelangt. dass dieselben von Terebinthus abstammen können. Sie unterscheiden sich wesentlich von der ersten Art, sind 4-6 Centimeter lang und 8-183 Millim. dick, mehr oder weniger gekrümmt, in eine scharfe Spitze endigend, mit ciner graulich-schwarzen Epidermis bedeckt, und zeigen 